\title{
B-cell clonality and infection with Helicobacter pylori: implications for development of gastric lymphoma
}

D Sorrentino, G F Ferraccioli, S DeVita, C Avellini, C A Beltrami, A Labombarda, V Bernardis, F De Biase, A Trevisi, B Pivetta, $M$ Boiocchi, E Bartoli

\begin{abstract}
Background-Although Helicobacter pylori has been implicated in the pathogenesis of gastric mucosa associated lymphoid tissue (MALT) and MALT lymphoma, it is not known how it may trigger these lesions and whether there is an identifiable pre-neoplastic stage.

Aims-To investigate the relation between MALT, $H$ pylori infection, and B-cell clonality (a potential marker of pre-neoplastic lesions).

Patients-141 subjects with simple dyspepsia.

Methods-Gastric biopsy specimens from all patients were examined for MALT and $H$ pylori. Of these, 25 consecutive MALT positive specimens were scored for features of MALT lymphoma and VDJ clonality studied by polymerase chain reaction.
\end{abstract}

Results-Overall, prevalence was $62 \%$ for $H$ pylori and $46 \%$ for MALT. VDJ clonality was frequent in the sub-group studied (nine of 25), mostly associated with lymphoid follicles (eight of nine or $89 \%$ ), and with a high scoring for MALT lymphoma. VDJ clonality was equally frequent in patients with and without $H$ pylori (seven of 20 and two of five or $35 \%$ and $40 \%$ respectively).

Departments of Internal Medicine D Sorrentino G F Ferraccioli A Labombarda V Bernardis F De Biase A Trevisi E Bartoli and Pathology C Avellini C A Beltrami

University of Udine, Udine, Italy

First Division of Experimental Oncology, Centro Riferimento Oncologico, IRCSS, Aviano, Italy $S$ DeVita B Pivetta

M Boiocchi

Correspondence to Dr D Sorrentino, Department of Internal Medicine, University of Udine, P le S Maria Misericordia 1, 33100 Udine, Italy.

Accepted for publication 13 December 1995
Conclusions-B-cell clonality is unexpectedly common in subjects with simple dyspepsia and MALT raising clinical management questions. These findings also suggest that the cascade MALT formation - B-cell clonality - MALT lymphoma may not be uniquely associated with $H$ pylori infection.

(Gut 1996; 38: 837-840)

Keywords: Helicobacter pylori, MALT, gastric lymphoma, B-cell clonality.

Little is known regarding the pathogenesis, clinical significance, and prognosis of gastric mucosa associated lymphoid tissue (MALT). It is thought to result from persistent antigenic stimulation of gastric mucosa leading to focal or diffuse lymphoid infiltration and to development of lymphoid follicles. As organised lymphoid tissue is not present in the normal gastric mucosa, development of gastric lymphoid follicles/MALT must be a necessary, though not sufficient, precursor lesion of gastric MALT lymphoma, ${ }^{1}$ a low grade lymphoma whose incidence has recently been shown to be increased in various parts of the world including north eastern Italy. ${ }^{2}$ Several epidemiological and experimental studies have linked Helicobacter pylori infection to both gastric lymphoid follicles ${ }^{3}$ and MALT lymphoma. ${ }^{4-8}$ Thus, it seems that persistent infection with $H$ pylori causes organised lymphocyte proliferation, which, in turn, can become autonomous and progress to a lymphoproliferative neoplastic disease. However, the various steps involved in the process and their potential reversibility are only just being explored.

Although its real biological meaning is still undefined, B-cell clonality is invariably present in lymphomas. ${ }^{9}$ Thus, clonal expansion of B-cells could represent an important event in the progression of a fully reactive lesion to neoplasia. ${ }^{10}$ In this study we explored this aspect in some detail. We first evaluated the prevalence of $H$ pylori infection and gastric lymphoid follicles in a north Italian patient population referred to us for simple dyspepsia. Then, in a group of patients of the same population, consecutively selected on the basis of the presence of gastric lymphoid infiltrates, we tested $\mathrm{IgH}$ gene clonality by polymerase chain reaction.

\section{Methods}

Patients

Patients included in the study were referred to our Digestive Diseases and Endoscopy Centre by general practitioners for a period of 10 months. The main reasons for referral included dyspepsia/heartburn or previous diagnosis of peptic ulcer/gastritis. After a preliminary check up in the outpatient clinic, patients had an upper endoscopy using standard Olympus video instruments. An average of five to six antral biopsy specimens were taken for histological examination, one for the rapid urease test (CLO from Delta West, Bentley, Australia), and three for molecular studies. Patients were classified as $H$ pylori positive or negative on the basis of both histological examination and CLO. When the two tests did not agree (two cases in total) classification was based on histological examination.

\section{Pathology}

Sections from formalin fixed, paraffin wax embedded gastric biopsy specimens were stained with haematoxylin and eosin and with 
a modified Giemsa stain and examined under the microscope by one of the investigators (CA) for the presence of inflammation, $H$ pylori, MALT (that is, lymphoid infiltrates or lymphoid follicles, the last defined as organised lymphatic tissue with defined germinal centres and the first representing scattered lymphocytes in the lamina propria of the gastric mucosa), and for features of MALT lymphoma according to Wotherspoon and colleagues. ${ }^{11}$ The features of inflammation were described according to known classifications. ${ }^{12} 13$

\section{Molecular studies}

For these studies, gastric biopsy specimens were immediately stored (without media) at $-70^{\circ} \mathrm{C}$ until use. B-cell clonality was assessed by VDJ polymerase chain reaction according to published methods. ${ }^{14}$ In brief, DNA was extracted from samples by standard procedures. Amplification of the IgH gene was performed using two protocols, FR3 and FR2. In the first, consensus primers for the $\mathrm{V}$ and $\mathrm{J}$ regions included, respectively, an upstream primer complementary to the third framework region (FR3) (5'ACACGGC[C/T][G/C]TGTATTACTGT-3') and a downstream primer directed to an outer conserved sequence of the J region (5'-TGAGGAGACGGTGACC$\left.3^{\prime}\right)$ in the first amplification round and to an inner conserved sequence of the same $J$ region (5'GTGACCAGGGTNCCTTGGCCCCAG- $3^{\prime}$ ) in the second amplification round. In the second protocol, the upstream primer was complementary to the second framework $\mathrm{V}$ region (FR2) of the IgH gene (5'-TGG[A/G] TCCG[C/A $]$ CAG[G/C $]$ C $[\mathrm{T} / \mathrm{C}][\mathrm{T} / \mathrm{C}] \mathrm{CNGG-}$ $\left.3^{\prime}\right)$. After amplification, analysis was conducted by agarose gel electrophoresis. The band pattern (one or two discrete bands: clonality, smear without dominant bands within the predicted size range: polyclonality) was evaluated after ethidium bromide staining and ultraviolet transillumination. Positive and negative controls (B-cell chronic leukaemia, reactive lymph node, or no DNA) were routinely analysed and compared with the test samples.

\section{Other studies}

Given the possible higher risk of patients with autoimmune diseases to develop MALT lymphomas ${ }^{15} 16$ all the patients testing positive for lymphoid follicles and VDJ clonality, irrespective of $H$ pylori infection, were screened for coexistent autoimmune diseases. The screening consisted of a history of suggestive symptoms and of a series of blood tests including erythrocyte sedimentation rate/C reactive protein, total immunoglobulins, rheumatoid factor, and autoantibody titre against nucleus, gastric mucosa, cytoplasmic antigen, smooth muscle, and DNA.

\section{Statistical analysis}

Statistical significance between prevalence rates was assessed by the $\chi^{2}$ test.
TABLE I Characteristics of patients $(n=141)$

\begin{tabular}{lc}
\hline Female/male & $72 / 69$ \\
Median age, years (range) & $52 \cdot 5(16-78)$ \\
Endoscopic diagnosis & \\
$\quad$ Antral gastritis & $105 / 141(74 \%)$ \\
Hiatal hernia/oesophagitis & $39 / 141(28 \%)$ \\
Peptic ulcer & $14 / 141(10 \%)$ \\
H pylori infection (by histology) & $88 / 141(62 \%)$ \\
Gastric lymphoid follicles & $65 / 141(46 \%)$ \\
Gastric lymphoid follicles with H pylori & \\
infection & $43 / 65(66 \%)$ \\
\hline
\end{tabular}

\section{Results}

\section{Patient population}

A total of 141 patients entered the study. Table I gives their main clinical, endoscopic, and histological features. In this population overall $H$ pylori prevalence was 88 of $141(62 \%)$ while gastric lymphoid follicles/infiltrates (as defined in Methods) were present in 65 of 141 patients (46\%). Of this group, $66 \%$ or 43 of 65 were associated with $H$ pylori infection. Overall, 31 of 141 or $22 \%$ of patients had neither $H$ pylori infection nor lymphoid follicles.

\section{VDf clonality}

As a further step to evaluate the possible pathogenesis and prognostic significance of gastric MALT we evaluated VDJ clonality in gastric biopsy specimens of a representative sample of the study population. Patients (25) were selected consecutively from the group of 65 showing lymphoid infiltrates on histological examination. When assessed for features of MALT according to Wotherspoon ${ }^{11}$ the score of the latter group as a whole was 0 in $5 \%, 1$ in $13 \%, 2$ in $55 \%$, and 3 in $27 \%$. In the 25 patients selected for molecular studies the score was similar ( 0 in $12 \%, 1$ in $12 \%, 2$ in $44 \%$, and 3 in $32 \%$ ) indicating that this sample was representative of the entire population. Of these 25 patients, 17 had organised gastric lymphoid follicles. Table II summarises the results.

(a) Of all patients with gastric lymphoid follicles VDJ clonality was present in eight of $17(47 \%)$ while only one of eight or $13 \%$ of patients without follicles showed clonality. Although showing a clear trend this difference did not reach statistical significance $(\mathrm{p}>0 \cdot 1) . H$ pylori infection was equally frequent in patients with and without follicles (13 of $17 v$ seven of eight or $77 \%$ v $88 \%$ respectively, $\mathrm{p}>0.9$ ).

TABLE II Molecular and histology studies

\begin{tabular}{lcc}
\hline & $G L F+(n=17)$ & $G L F-(n=8)$ \\
H pylori infection & $13 / 17(77 \%)$ & $7 / 8(88 \%)$ \\
VDJ clonality & $8 / 17(47 \%)$ & $1 / 8(13 \%)$ \\
& $H P I+(n=20)$ & $H P I-(n=5)$ \\
Gastric lymphoid follicles & $13 / 20(65 \%)$ & $4 / 5(80 \%)$ \\
VDJ clonality & $7 / 20(35 \%)$ & $2 / 5(40 \%)$ \\
& $V D f c+(n=9)$ & $V D f_{c}-(n=16)$ \\
Gastric lymphoid follicles & $8 / 9(89 \%)$ & $9 / 16(56 \%)$ \\
Hpylori infection & $7 / 9(78 \%)$ & $13 / 16(81 \%)$ \\
\hline
\end{tabular}

GLF = patients with $(+)$ or without $(-)$ gastric lymphoid follicles; HPI = patients with $(+)$ or without $(-)$ H pylor clonality; $n=$ number of patients. 
(b) Of all patients infected with $H$ pylori one of three (seven of 20 or $35 \%$ ) had VDJ clonality. A similar figure was seen in uninfected patients (two of five or $40 \%, \mathrm{p}>0 \cdot 7$ ).

(c) Of all patients with VDF clonality most (eight of nine or $89 \%$ ) had lymphoid follicles and $H$ pylori infection (seven of nine or $78 \%$ ). Again, these numbers were not significantly different from the respective controls (nine of 16 or $56 \%$ and 13 of 16 or $81 \%$ ) with p values greater than 0.2 and 0.7 respectively.

Of note, a much greater proportion of patients with B-cell clonality compared with patients without, had a high grade histological scoring according to Wotherspoon et al. ${ }^{11} \mathrm{In}$ particular, grade 3 was present in five of nine $(56 \%)$ patients with VDJ clonality compared with three of $16(19 \%)$ patients without clonality. Because of the small number of samples, however, the difference did not reach statistical significance $(p>0 \cdot 1)$.

None of the patients in question showed abnormalities with regard to autoimmune disorders as defined in Methods.

\section{Discussion}

Gastric MALT lymphoma is the most common extranodal non-Hodgkin's lymphoma. To date, clear cut identification of potentially preneoplastic lesions is difficult. Other important aspects of this tumour to be clarified relate to the precise definition of the different stages of lymphomagenesis and to the study of the factors that begin and maintain the process.

Recently, it has been shown that when B-cell clonality is demonstrated together with defined histological features a diagnosis of low grade MALT lymphoma can be done with a great degree of confidence. ${ }^{1718}$ As all lymphomas are monoclonal ${ }^{9}$ but not all lesions with evidence of clonal B-cell expansion are neoplastic ${ }^{19}$ it seems that B-cell clonality must precede and eventuate in lymphoma. ${ }^{10}$ Thus, B-cell clonality could represent an important feature, a potential marker, of pre-neoplastic lesions.

Similarly to gastric carcinoma, MALT lymphoma of the stomach has been associated with $H$ pylori infection. ${ }^{24} 5112021$ In this study, aimed at characterising prelymphomatous states, we have tried to define in some detail the role of $H$ pylori infection and gastric lymphoid follicles in the genesis of gastric B-cell clonality in a north Italian patient population referred to us for dyspepsia.

By contrast with that observed by others ${ }^{3}$ a small but significant number of our patients had lymphoid follicles without $H$ pylori infection and, vice versa, $H$ pylori infection without lymphoid follicles. Although other explanations are possible this finding suggests, on the one hand, that stimuli other than $H$ pylori may cause formation of lymphoid follicles and, on the other hand, that an individual immune response to this bacterium and to other antigenic stimuli may be needed to produce lymphoid follicles.
In a representative group of patients from this population showing lymphoid infiltrates (Table II) VDJ clonality was very common in the presence of organised gastric lymphoid follicles. This is consistent with the finding that patients with clonality tended to have a higher histological scoring for diagnosis of MALT lymphoma. Table II also shows that B-cell clonality is equally frequent in $H$ pylor infected patients and in uninfected subjects. This finding is apparently inconsistent with the currently held opinion that $H$ pylori plays a crucial part in the pathogenesis of gastric MALT lymphoma. ${ }^{22}$ Indeed, preliminary data ${ }^{23-26}$ suggest that not only $H$ pylori but also other infectious agents and possibly other mechanisms could, perhaps by a continuous antigenic stimulation of gastric mucosa, give rise to organised MALT/lymphoid follicles and to a cascade of events leading to B-cell clonality and malignancy. ${ }^{10}$ Autoimmunity also may, in this regard, play an important part. ${ }^{27}$ Although $H$ pylori may not be the only pathogen involved in MALT genesis and B-cell clonality it may still be the most common, given the high prevalence of $H$ pylori infection among the general population.

Another finding of potential clinical importance of our study is the unexpectedly high prevalence of B-cell clonality in patients with simple dyspepsia and lymphoid infiltrates. Given the comparatively low frequency of clinical MALT lymphoma in the general population, this finding raises questions regarding the real prognostic and epidemiological significance of B-cell clonality. Thus, the latter could be a very early step in the process of oncogenesis: the development of lymphoma, requiring several other events, would occur only in a very restricted fraction of patients. Alternatively, if B-cell clonality is indeed only a few steps away from gastric MALT lymphoma, this, especially in subclinical forms, must be greatly underdiagnosed at the moment. With the data currently available it is difficult to provide a convincing answer to this question. As already mentioned, in the group with clonality, compared with the group without, there was a higher percentage of patients with grade 3 histological scoring for diagnosis of MALT lymphoma according to the system proposed by the group of Isaacson. ${ }^{11}$ Careful follow up of the patients with B-cell clonality with and without eradication (when feasible) of the triggering antigenic stimulus may shed light in this regard. Initial studies in patients with autoimmune diseases ${ }^{26}$ and dyspepsia (Sorrentino et al, unpublished findings) do not show a clear cut temporal relation between $H$ pylori infection and B-cell clonality.

In conclusion, our study suggests that once an antigenic stimulus has caused an initial immune reaction, a factor must exist that predisposes a given patient to the development of MALT lymphoma. B-cell clonal expansion is a necessary, though insufficient, step. It would be extremely important to ascertain whether a particular genetic/immunological make up (for example, HLA type) would expose a given patient to a greater risk of developing 
neoplasia. At the moment, these data collectively suggest that treatment of everybody infected with $H$ pylori could play a part in the prevention of gastric MALT lymphoma. ${ }^{28} 29$ These and other aspects of gastric preneoplastic lesions are being actively investigated in our unit.

The content of this paper was partially presented and published in abstract form at the World Congress of Gastroenterology, Los Angeles CA, USA 2-7 October 1994, proceedings, 721. Los Angeles CA, USA 2-7 October 1994, proceedings, 721.
Supported in part by Grant 93.0440.CT04, AIRC Supported in part by Grant $93.0440 . C T 04$, AIRC
(Ministero Sanita 1994) and CNR special project ACRO (Ministero Sanità
(95.00504.PF39).

1 Isaacson PG. Lymphomas of mucosa-associated lymphoid tissue (MALT). Histopathology 1990; 16: 617-9.

2 Doglioni C, Wotherspoon AC, Moschini A, DeBin M, Isaacson PG. High incidence of primary gastric lymphoma in northeastern Italy. Lancet 1992; 339: 834-5.

3 Genta RM, Hamner HW, Graham DY. Gastric lymphoid follicles in Helicobacter pylori infection: frequency, distribution and response to triple therapy. Hum Pathol 1993; 24: 577-83.

4 Parsonnet J, Hansen S, Rodriguez L, Gelb AB, Warnke LA, Jellum E, et al. Helicobacter pylori infection and gastric Jellum E, et al. Helicobacter pylori infection a

5 Hussell T, Isaacson PG, Crabtree JE, Spencer J. The response of cells from low-grade B-cell gastric lymphoma of mucosa-associated lymphoid tissue to Helicobacter pylori. Lancet 1993; 342: 571-4.

6 Wotherspoon AC, Ortiz-Hidalgo C, Falzon MR, Isaacson PG. Helicobacter pylori associated gastritis and primary B-cell gastric lymphoma. Lancet 1991; 338: 1175-6.

7 Isaacson PG, Spencer J. Is gastric lymphoma an infectious disease? Hum Pathol 1993; 24: 569-70.

8 Isaacson PG. Gastric lymphoma and Helicobacter pylori. $N$ Engl f Med 1994; 330: 1310-1.

9 Sanchez L, Algara P, Villuendas R, Martinez P, Orradre JL, Morente $\mathrm{M}$, et al. B-Cell clonal detection in gastric lowgrade lymphomas and regional lymph nodes: an immunohistologic and molecular study. Am $\mathcal{F}$ Gastroenterol 1993; 88: 413-9.

10 Sigal SH, Saul SH, Auerbach HE, Raffensperger E, Kant JE, Brooks JJ. Gastric small lymphocytic proliferation with immunoglobulin gene rearrangement in pseudolymphoma versus lymphoma. Gastroenterology 1989; 97: 195-201.

11 Wotherspoon AC, Doglioni C, Diss TC, Pan L, Moschini A, deBoni M, et al. Regression of primary low-grade B-cell gastric lymphoma of mucosa-associated lymphoid tissue type after eradication of Helicobacter pylori. Lancet 1993; 342: $575-7$.

12 Price AB. The Sydney system histological division. $f$ Gastroenterol Hepatol 1991; 6: 209-22.

13 Whitehead R, Truelove SC, Gear MW. The histologic diagnosis of chronic gastritis in fiberoptic gastroscope biopsy specimen. 7 Clin Pathol 1972; 25: 1-11.

14 DeVita S, Ferraccioli GF, DeRe V, Dolcetti R, Carbone A, Bartoli E, Boiocchi M. The polymerase chain reaction detects B cell clonalities in patients with Sjögren's syndrome and suspected malignant lymphoma. $\mathcal{F}$ Rheumatol 1994; 21: 1497-501.

15 Diss TC, Peng H, Wotherspoon AC, Pan L, Speight PM, Isaacson PG. Brief report: a single neoplastic clone in sequential biopsy specimens from a patient with primary gastric-mucosa-associated lymphoid-tissue lymphoma
and Sjögren's syndrome. N Engl f Med 1993; 329: 172-5.

16 Isaacson PG, Spencer J. Malignant lymphoma and autoimmune disease. Histopathology 1993; 22: 509-10.

17 Thomas GA, Williams D. Gastric lymphomas [Letter]. Lancet 1993; 342: 1182 .

18 Isaacson PG, Spencer J. Gastric lymphomas [Letter reply]. ancet 1993; 342: 1183.

19 Galton DA, Catovsky D, Wiltshaw E. Clinical spectrum of lymphoproliferative diseases. Cancer 1978; 42: 901-10.

20 Bayerdorffer E, Neubauer A, Rudolph B, Thiede C, Lehn $\mathrm{N}$, Eidt $\mathrm{S}$, et al. Regression of primary gastric lymphoma of mucosa-associated lymphoid tissue type after cure of Helicobacter pylori infection. Lancet 1995; 345: 1591-4.

21 Stolte $M$, Eidt $S$. Healing gastric MALT lymphoma by eradicating H pylori? Lancet $1993 ; 342: 568$.

22 Eidt S, Stolte M, Fischer R. Helicobacter pylori gastritis and primary gastric non-Hodgkin's lymphomas. $\mathcal{f}$ Clin Pathol 1994; 47: 436-9.

23 Sorrentino D, Ferraccioli GF, DeVita S, Avellini C, Beltrami CA, Trevisi A, et al. VDJ clonality in patients with gastric lymphoid follicles: role of Helicobacter pylori infection. 10th World Congress of Gastroenterology, Los Angeles CA, proceedings 1994: P721.

24 Sorrentino D, Ferraccioli GF, DeVita S, Avellini C, Beltrami CA, Trevisi A, et al. Gastric lymphoid follicles: prevalence in patients with dyspepsia and with autoimmune diseases and relationship with Helicobacter pylori infection [Abstract]. Gastroenterology 1994; 106: A183.

25 Ferraccioli GF, Sorrentino D, DeVita S, Avellini C, DeRe $\mathrm{V}$, Beltrami CA, et al. Lymphoid follicles in gastric mucosa of Sjögren's patients: evidence of monoclonal mucosa of Sjogren's patients: evidence of monoclonal transformation and relationship with Helicobacte

26 Ferraccioli GF, Sorrentino D, DeVita S, Casatta L, Avellini C, Beltrami CA, et al. B-cell clonality in gastric lymphoid tissues of patients with Sjögren's syndrome. Ann Rheum Dis (in press).

27 Greiner A, Marx A, Heesemann J, Leebmann J, Schmausser $B$, Muller-Hermelink HK. Idiotype identity in a MALTtype lymphoma and B-cells in Helicobacter pylori associated chronic gastritis. Lab Invest 1994; 70: 572-8.

28 Al-Saleem T. Gastric lymphomas [Letter reply]. Lancet 1993; 342: 1184 .

29 Savio A, Franzin G, Wotherspoon AC, Zamboni G, Negrini $\mathrm{R}$, Buffoli $\mathrm{F}$, et al. Diagnosis and post-treatment follow-up
of $\mathrm{H}$ pylori-positive gastric lymphoma of mucosa-associof $\mathrm{H}$ pylori-positive gastric lymphoma of mucosa-associated lymphoid tissue: histology, pol 